\title{
Computer vision syndrome: Are medical students exempted from it?
}

\author{
Rupali Maheshgaori', Parag Apte ${ }^{2}$, Deepaswi Bhavsar ${ }^{3, *}$, Gaurav Bramhabhatt ${ }^{4}$, Prachi Bakre $^{5}$ \\ ${ }^{\mathbf{1}}$ Associate Professor, ${ }^{2,5}$ Assistant Professor, ${ }^{3}$ Senior Resident, ${ }^{4}$ Junior Resident, Dept. of Ophthalmology, Dr. D.Y Patil Medical \\ College, Hospital \& Research Centre, Pimpri, Pune, Maharashtra, India
}

*Corresponding Author:

Email: deepaswibhavsar@gmail.com

\begin{abstract}
Introduction: It has been observed that use of computer by medical students is increasing. Study material is becoming more digital, computers are used in many of the diagnostic tests that take place within the hospital. This study was conducted with the aim to study the prevalence, risk factors and clinical evaluation and spread awareness of computer vision syndrome among medical students.

Materials and Methods: This Cross sectional study was conducted at a Medical college in Pune. The questionnaire was allotted to students in campus of medical College, those who were found to be symptomatic were further evaluated in Out Patient Department of Ophthalmology data analyzed by using SPSS software version 17.0. Statistical tools used were proportions \& percentages \& other appropriate. Statistical tests of significance applied.

Result: the prevalence of computer vision syndrome was $54.44 \%$. using computers for 6 -8hours have higher percentage $(39.12 \%) \&$ duration more than 6-8 years of using computers $29.02 \%$ students suffering from computer vision syndrome (cvs). ocular \& non ocular symptomps were statistically significant.

Conclusion: The prevalence of computer vision syndrome amongst medical student was $54.44 \%$. Factors to relieve symptoms were also studied and it is found that awareness of CVS definitely reduce symptoms.
\end{abstract}

Keywords: Computer vision syndrome, Digital eye strain, Visual display unit.

\section{Introduction}

The digital revolution has launched a new era of human empowerment, Never before has there been a more powerful influence on human behavior, irrespective of work profile, country or culture, bys the combined effect of digital technologies. Technological advances create incredible new solutions, but present new difficulties as well.

Computers, Ipads, cell phones with visual display units (VDU); have made day to day activity effortless in all fields of life. All this productivity often means that we spend a lot of time staring at screens: our work computers, our home laptops, and our smartphones. Computers with visual display units (VDU) have been made smarter moving from desk to mobile phones. It has also led to increased number of patients complaining about ocular and non ocularsymptoms. ${ }^{1}$ The increasing use of computers has brought about a much higher incidence of various health problems: visual complaints, ocular and extraocular discomfort (headache and musculoskeletal problems. ${ }^{1-3}$

Computer Vision Syndrome, (CVS) referred to as digital eye strain, describes a group of eye and visionrelated problems that result from prolonged computer, tablet, e-reader and cell phone use. According to the US National Institute for Occupational Safety and Health, computer vision syndrome affects about $90 \%$ of the people who spend three hours or more a day at a computer. ${ }^{4}$ It has been observed that use of computer by medical students is also increasing. Study material is becoming more digital, portable document format (PDF) aided lectures are taken for better understanding, computers arSe used in many of the diagnostic tests that take place within the hospital as well as use of internet has also increased concerning to study material, surgical videos, communication, transfer of iles. Nowadays Computers are just not restricted to offices or particular occupation but has found a way into every individual's lifestyle. Thus the present study was designed to assess the prevalence of Computer Vision Syndrome (CVS) among medical students and modifiable ergonomic factors associated with the same.

\section{Materials and Methods}

This study was conducted with the aim to study the prevalence, risk factors and clinical evaluation of computer vision syndrome among medical students.

This cross sectional study was conducted at a Medical college in Pune. The study consisted of a questionnaire and ophthalmic evaluation. The questionnaire was allotted to students in campus of medical college, for clinical evaluation students were examined at ophthalmology outpatient department of the Medical College. The duration of the study was 6 months. All under graduate and post graduate students who worked daily on computers, used mobile phones and tablets prior to starting the study were included. Students with history of refractive surgery and any other ocular surgery, students on eye drops for any ocular conditions at time of study were excluded. Thus by using the above mentioned inclusion and exclusion criteria total 709 students were enrolled.

Institute Ethics Committee Clearance was obtained before starting the study. Also the permission was taken from The Dean of Medical College to interview their students. The participants were surveyed using a 
structured questionnaire based on the knowledge of previous studies, which included the basic demographic profile, hours of computer use per day, frequency of break taken while working on computers.

Those who were found to be symptomatic were further evaluated in Out Patient Department of Ophthalmology of Medical College, Hospital and Research Centre, Pune. Computer vision syndrome is defined as "the complex of eye and vision problems related to near work, which are experienced during or related to computer use has been termed "CVS". 5 The eye symptoms were redness, burning sensation of eye, headache, blurred vision and dry eyes etc. ${ }^{6,7}$ these symtoms were assesed on a likert scale like always, sometimes, never. Students' demographic, personal details including name, age, sex, OPD number, occupation, place of residence, qualification was recorded. Also all students were evaluated for any systemic illness or whether they are having any past history of ocular trauma or history of any medication and were recorded in Pro-forma. A detailed ocular history as well as past and personal history was recorded. General ophthalmic examination of both eyes was performed, vision assessment uncorrected visual acuity [UCVA], pinhole, best corrected visual acuity [BCVA], near vision were assesed using Snellen's chart, anterior segment examination was done on Slit lamp, Fundus examination through undiated pupil was done on slit lamp with aid of +90 Diopter lens. For staining tests fluroscein impregnated strips were used, Tear break up time (TBUT) is recorded A TBUT value $<10 \mathrm{~s}$ was considered abnormal. Schirmer test was performed without topical anesthesia using standardized Whatman filter paper., ${ }^{89}$

\section{Data Collection:}

\section{Step I: Designing of Questionnaire.}

A semi-structured questionnaire was prepared and validated with study subject and study expert in peer and modified with reference to study objectives.

Step II: The semi-structured questionnaire was administered to the medical students who meet the eligibility criteria

Step III: Information was obtained from students including personal baseline data profile, Symptoms \& Signs of computer vision syndrome were looked for in opd.

Data Analysis: Data analysis of the present study includes following steps.

Step I: all responses were tabulated by the investigator using Microsoft-Excel 2007 Software. Graphical representations were made wherever necessary.

Step II: Data analyzed by using SPSS software version 17.0. Statistical tools used were proportions \& percentages \& other appropriate. Statistical tests of significance.

\section{Results}

The present study was conducted among the medical students. Total number of students enrolled were 709.

\section{Table 1: Prevalence of CVS}

\begin{tabular}{|l|c|c|}
\hline & Number & \% \\
\hline CVS present & 386 & $54.44 \%$ \\
\hline CVS absent & 323 & $45.56 \%$ \\
\hline Total & 709 & 100 \\
\hline
\end{tabular}

In the present study the prevalence of computer vision syndrome was $54.44 \%$.

Table 2: Average hours spent on computer daily

\begin{tabular}{|l|c|c|}
\hline Hrs/Day & Number & \% \\
\hline 1-2 hours & 81 & $20.98 \%$ \\
\hline 3-5 hours & 123 & $31.87 \%$ \\
\hline 6-8 hours & 151 & $39.12 \%$ \\
\hline$>8$ hours & 31 & $8.03 \%$ \\
\hline Total & 386 & \\
\hline
\end{tabular}

It was seen that majority of the students suffering from computer vision syndrome were using computer, laptop, mobile phone daily (VDU) for 6-8hours $(39.12 \%)$ followed by $3-5$ hours $(31.87 \%)$ and $1-2$ hours (20.98\%).

Table 3. Duration of computer use

\begin{tabular}{|l|c|c|}
\hline \multicolumn{3}{|c|}{ Duration of computer use } \\
\hline \multicolumn{1}{|c|}{ Duration } & Number & $\%$ \\
\hline$<1$ year & 5 & $1.30 \%$ \\
\hline 1-2 years & 62 & $16.06 \%$ \\
\hline 3-5 years & 110 & $28.50 \%$ \\
\hline 6-8 years & 112 & $29.02 \%$ \\
\hline$>8$ years & 97 & $25.13 \%$ \\
\hline Total & 386 & \\
\hline
\end{tabular}

It was observed that $29.02 \%$ students suffering from computer vision syndrome were using computers with visual display units since 6-8years whereas $28.50 \%$ students using computers since 3-5 years. Majority of the medical students were using computers with VDU since 3-8 years.

Table 4: CVS symptoms

\begin{tabular}{|l|c|c|}
\hline \multicolumn{1}{|c|}{ Symptoms } & Number & \% \\
\hline Headache & 206 & $53.37 \%$ \\
\hline Eye strain & 178 & $46.11 \%$ \\
\hline Dry eye & 150 & $38.86 \%$ \\
\hline Blurred vision & 119 & $30.83 \%$ \\
\hline Watery eye & 51 & $13.21 \%$ \\
\hline Red eye & 21 & $5.44 \%$ \\
\hline Discomfort & 9 & $2.33 \%$ \\
\hline Double vision & 2 & $0.52 \%$ \\
\hline
\end{tabular}


The most common presenting symptom observed among the study students was headache $(53.37 \%)$ followed by eye strain $(46.11 \%)$ and dry eye $(38.86 \%)$.

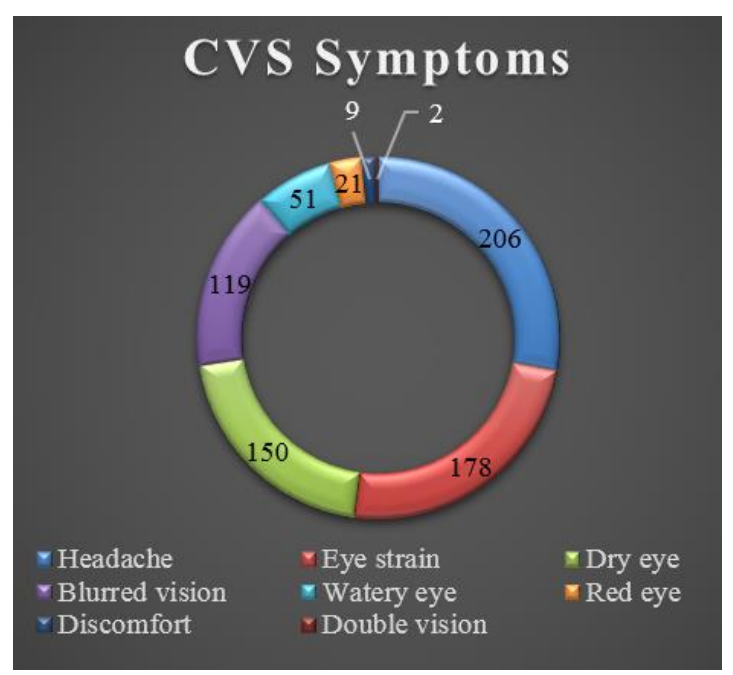

Table 5: Non-ocular symptoms observed in students along with CVS

\begin{tabular}{|l|c|c|}
\hline & Number & \% \\
\hline Neck pain & 46 & $11.92 \%$ \\
\hline Backache & 34 & $8.81 \%$ \\
\hline Shoulder pain & 21 & $5.44 \%$ \\
\hline
\end{tabular}

In the present study it was observed that among the non-ocular symptoms neck pain $(11.92 \%)$ was the most common presenting symptom.

Table 6: Relation between CVS symptoms and the average number of hours spent on computer

\begin{tabular}{|c|c|c|c|c|c|c|c|}
\hline \multicolumn{2}{|l|}{ Hours } & 1-2hrs & 3-5hrs & 6-8hrs & $>8 \mathrm{hrs}$ & Total & P value \\
\hline \multirow[t]{2}{*}{ Headache } & $\mathrm{Y}$ & 27 & 70 & 111 & 22 & 230 & \multirow[t]{2}{*}{$0.000 *$} \\
\hline & $\mathrm{N}$ & 39 & 56 & 44 & 16 & 156 & \\
\hline \multirow[t]{2}{*}{ Eye strain } & $\mathrm{Y}$ & 22 & 52 & 119 & 2 & 195 & \multirow[t]{2}{*}{$0.000 *$} \\
\hline & $\mathrm{N}$ & 44 & 75 & 36 & 36 & 191 & \\
\hline \multirow[t]{2}{*}{ Dry eye } & $\mathrm{Y}$ & 4 & 4 & 131 & 37 & 177 & \multirow[t]{2}{*}{$0.000^{*}$} \\
\hline & $\mathrm{N}$ & 62 & 123 & 24 & 1 & 209 & \\
\hline \multirow[t]{2}{*}{ Blurred vision } & $\mathrm{Y}$ & 22 & 37 & 55 & 16 & 130 & \multirow[t]{2}{*}{0.161} \\
\hline & $\mathrm{N}$ & 45 & 89 & 100 & 22 & 256 & \\
\hline \multirow[t]{2}{*}{ Watery eye } & $\mathrm{Y}$ & 6 & 4 & 46 & 3 & 59 & \multirow[t]{2}{*}{$0.000 *$} \\
\hline & $\mathrm{N}$ & 60 & 123 & 109 & 35 & 327 & \\
\hline \multirow[t]{2}{*}{ Red eye } & $\mathrm{Y}$ & 5 & 6 & 21 & 0 & 32 & \multirow[t]{2}{*}{$0.000 *$} \\
\hline & $\mathrm{N}$ & 62 & 121 & 134 & 38 & 354 & \\
\hline \multirow[t]{2}{*}{ Discomfort } & $\mathrm{Y}$ & 10 & 9 & 2 & 0 & 21 & \multirow[t]{2}{*}{$0.000 *$} \\
\hline & $\mathrm{N}$ & 56 & 118 & 153 & 38 & 365 & \\
\hline \multirow[t]{2}{*}{ Double vision } & $\mathrm{Y}$ & 0 & 0 & 1 & 0 & 1 & \multirow[t]{2}{*}{0.394} \\
\hline & $\mathrm{N}$ & 66 & 127 & 154 & 38 & 385 & \\
\hline
\end{tabular}

* Statistically Significant

In the present study relation between symptoms of computer vision syndrome and average number of hours spent on computer was studied. And it was observed that majority of the symptoms were having statistically significant association with increasing hours of computer use.

Table 7: Relation between non ocular symptoms and the average number of hours spent on computer

\begin{tabular}{|l|c|c|c|c|c|c|c|}
\hline Hours & & $\mathbf{1 - 2 h r s}$ & $\mathbf{3 - 5 h \mathbf { h }}$ & $\mathbf{6 - 8 h r}$ & $\mathbf{> 8 h \mathbf { h }}$ & Total & P value \\
\hline \multirow{2}{*}{ Neck pain } & $\mathrm{Y}$ & 6 & 9 & 40 & 5 & 60 & $0.000^{*}$ \\
\cline { 2 - 8 } & $\mathrm{N}$ & 60 & 118 & 115 & 33 & 326 & \\
\hline \multirow{2}{*}{ Backache } & $\mathrm{Y}$ & 9 & 14 & 20 & 4 & 46 & 0.759 \\
\cline { 2 - 8 } & $\mathrm{N}$ & 57 & 113 & 135 & 34 & 340 & \\
\hline & & & & & & & \\
\hline $\begin{array}{l}\text { Shoulder } \\
\text { pain }\end{array}$ & $\mathrm{Y}$ & 3 & 5 & 15 & 4 & 27 & $0.016^{*}$ \\
\cline { 2 - 7 } & $\mathrm{N}$ & 63 & 122 & 140 & 34 & 359 & \\
\hline
\end{tabular}

* Statistically Significant 
It was seen that neck pain and shoulder pain had significant association with the average numbers of hours spent on computer.

Table 8: Relation between CVS symptoms and the duration of computer use

\begin{tabular}{|c|c|c|c|c|c|c|c|c|}
\hline 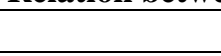 & & $<1$ year & 1-2 years & 3-5 years & 6-8 years & $>8$ years & Total & P value \\
\hline \multirow{2}{*}{ Headache } & $\mathrm{Y}$ & 2 & 33 & 78 & 96 & 22 & 230 & \multirow{2}{*}{$0.000^{*}$} \\
\hline & $\mathrm{N}$ & 24 & 39 & 36 & 14 & 43 & 156 & \\
\hline \multirow{2}{*}{ Eye strain } & $\mathrm{Y}$ & 11 & 25 & 56 & 84 & 19 & 195 & \multirow{2}{*}{$0.000^{*}$} \\
\hline & $\mathrm{N}$ & 15 & 46 & 58 & 26 & 46 & 191 & \\
\hline \multirow{2}{*}{ Dry eye } & $\mathrm{Y}$ & 2 & 5 & 22 & 85 & 64 & 177 & \multirow{2}{*}{$0.000^{*}$} \\
\hline & $\mathrm{N}$ & 24 & 67 & 93 & 25 & 1 & 209 & \\
\hline \multirow{2}{*}{ Blurred vision } & $\mathrm{Y}$ & 2 & 21 & 37 & 54 & 17 & 130 & \multirow{2}{*}{$0.000 *$} \\
\hline & $\mathrm{N}$ & 24 & 51 & 78 & 55 & 48 & 256 & \\
\hline \multirow{2}{*}{ Watery eye } & $\mathrm{Y}$ & 2 & 5 & 3 & 47 & 3 & 59 & \multirow{2}{*}{$0.000 *$} \\
\hline & $\mathrm{N}$ & 24 & 66 & 112 & 62 & 62 & 327 & \\
\hline \multirow{2}{*}{ Red eye } & $\mathrm{Y}$ & 2 & 4 & 5 & 21 & 0 & 32 & \multirow{2}{*}{$0.000 *$} \\
\hline & $\mathrm{N}$ & 24 & 67 & 109 & 89 & 65 & 354 & \\
\hline \multirow{2}{*}{ Discomfort } & $\mathrm{Y}$ & 8 & 10 & 0 & 2 & 1 & 21 & \multirow{2}{*}{$0.000^{*}$} \\
\hline & $\mathrm{N}$ & 18 & 62 & 115 & 107 & 64 & 365 & \\
\hline \multirow{2}{*}{ Double vision } & $\mathrm{Y}$ & 0 & 0 & 0 & 1 & 1 & 1 & \multirow{2}{*}{0.599} \\
\hline & $\mathrm{N}$ & 26 & 72 & 115 & 109 & 64 & 385 & \\
\hline
\end{tabular}

* Statistically Significant

The Relation between CVS symptoms and the Duration of computer use was also studied. It was observed that there was significant association between the duration of computer use and symptoms

Table 9: Relation between non ocular symptoms and the duration of computer use

\begin{tabular}{|l|c|c|c|c|c|c|c|c|}
\hline \multicolumn{2}{|c|}{} & $<1$ year & $\mathbf{1 - 2}$ years & $\begin{array}{c}\mathbf{3 - 5} \\
\text { years }\end{array}$ & $\begin{array}{c}\mathbf{6 - 8} \\
\text { years }\end{array}$ & $\mathbf{> 8}$ years & Total & \multirow{2}{*}{ P value } \\
\hline \multirow{2}{*}{ Neck pain } & $\mathrm{Y}$ & 2 & 7 & 11 & 30 & 11 & 60 & \multirow{2}{*}{$0.000^{*}$} \\
\cline { 2 - 10 } & $\mathrm{N}$ & 24 & 65 & 104 & 79 & 54 & 326 & \\
\hline \multirow{2}{*}{ Backache } & $\mathrm{Y}$ & 2 & 12 & 11 & 14 & 7 & 46 & 0.364 \\
\cline { 2 - 10 } & $\mathrm{N}$ & 24 & 60 & 104 & 95 & 57 & 340 & \\
\hline \multirow{2}{*}{ Shoulder pain } & $\mathrm{Y}$ & 1 & 4 & 5 & 11 & 6 & 27 & \multirow{2}{*}{0.089} \\
\cline { 2 - 9 } & $\mathrm{N}$ & 25 & 67 & 110 & 98 & 58 & 359 & \\
\hline
\end{tabular}

* Statistically Significant.

It was seen that neck pain had significant association with duration of computer use.

Table 10: Risk factors for CVS

\begin{tabular}{|l|c|c|}
\hline Risk Factors & Number & \% of Total CVS present \\
\hline Prolonged glaring at the screen & 265 & $68.65 \%$ \\
\hline Long work duration & 165 & $42.75 \%$ \\
\hline Use of too much mental strength & 109 & $28.24 \%$ \\
\hline Too bright screen/ light & 92 & $23.83 \%$ \\
\hline External light reflection on the computer screen & 46 & $11.92 \%$ \\
\hline Poor eyesight & 48 & $12.44 \%$ \\
\hline Stress & 43 & $11.14 \%$ \\
\hline Personal fatigue & 35 & $9.07 \%$ \\
\hline Poor ventilation & 31 & $8.03 \%$ \\
\hline
\end{tabular}

Various risk factors have been observed to be associated computer vision syndrome. Prolonged glaring at the screen was reported by $68.65 \%$ of students followed by long work duration $(42.78 \%)$ and use of too much mental strength (28.24\%). Too bright screen/ light $(23.83 \%)$, external light reflection on the computer screen $(11.92 \%)$, poor eyesight $(12.44 \%)$, stress $(11.14 \%)$, personal fatigue $(9.07 \%)$ and poor ventilation $(8.03 \%)$ were the other risk factors observed in the present study.I 


\section{Graph 1:}

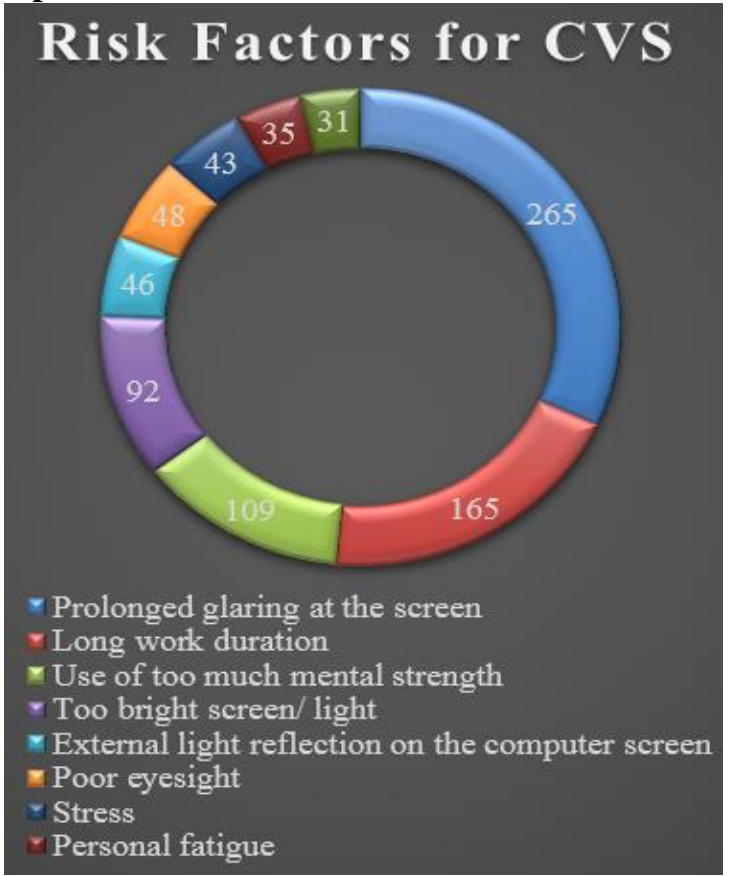

Table 11 Measure taken by students to get relief from computer-related symptom

\begin{tabular}{|l|c|c|}
\hline \multicolumn{1}{|c|}{ Measure } & Number & \% \\
\hline Taking regular breaks & 136 & $35.23 \%$ \\
\hline Blinking frequently & 92 & $23.83 \%$ \\
\hline Close eyes & 123 & $31.87 \%$ \\
\hline Checking eyes regularly & 87 & $22.54 \%$ \\
\hline $\begin{array}{l}\text { Using glare screen on the } \\
\text { computer }\end{array}$ & 109 & $28.24 \%$ \\
\hline Nothing & 129 & $33.42 \%$ \\
\hline
\end{tabular}

It was observed that $35.23 \%$ students were taking regular breaks to get relief from the computer vision syndrome. Closing eyes $(31.87 \%)$ and using glare screen on the computer $(28.24 \%)$ were the other measures used by the students.

\section{Graph 2:}

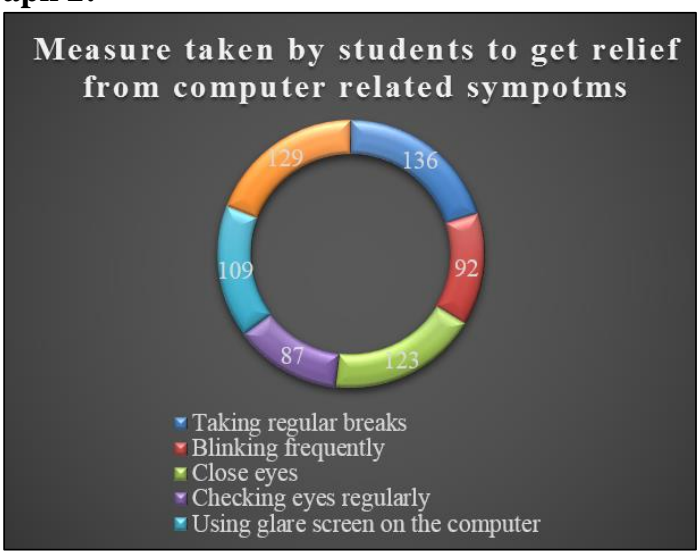

Table No 12. Schirmer's test result

\begin{tabular}{|l|c|c|c|c|}
\hline Scale & 1-2hrs & 3-5hrs & 6-8hrs & $>$ 8hrs \\
\hline $0-5 \mathrm{~mm}$ & 4 & 10 & 36 & 58 \\
\hline $6-10 \mathrm{~mm}$ & 10 & 31 & 43 & 71 \\
\hline$>10 \mathrm{~mm}$ & 77 & 27 & 14 & 4 \\
\hline
\end{tabular}

It was observed that schirmer's test result less than $5 \mathrm{~mm}$ was found in $94(24.35 \%)$ students using computers more than 6 hours.

\section{Graph 3:}

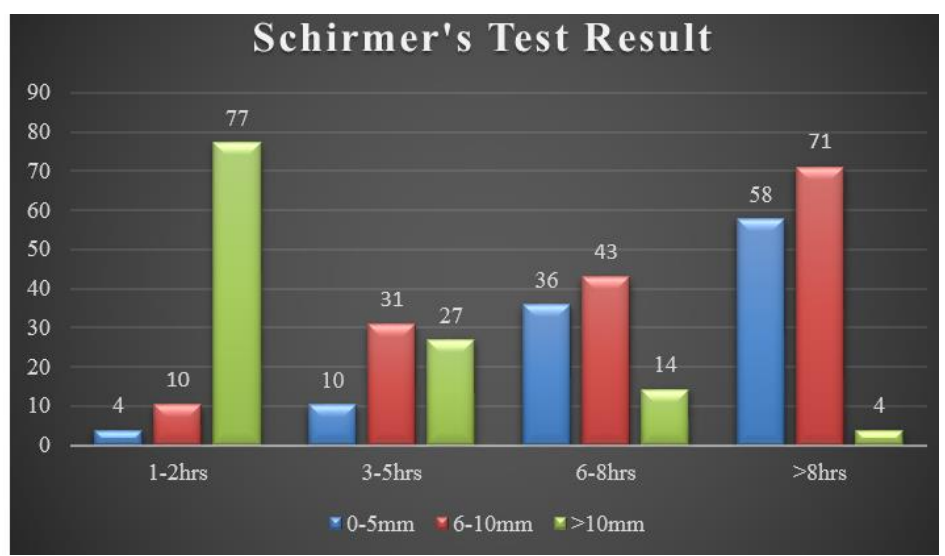

Table 13: Tear break-up time test result

\begin{tabular}{|l|c|c|c|c|}
\hline \multicolumn{5}{|c|}{ Tear Break-up Time Test } \\
\hline Time & $\mathbf{1 - 2 h r s}$ & $\mathbf{3 - 5 h r s}$ & $\mathbf{6 - 8 h r s}$ & $\mathbf{> 8 h r s}$ \\
\hline $0-4 \mathrm{Sec}$ & 0 & 7 & 46 & 54 \\
\hline $5-10 \mathrm{Sec}$ & 39 & 31 & 35 & 61 \\
\hline$>10 \mathrm{Sec}$ & 77 & 31 & 4 & 1 \\
\hline
\end{tabular}

Tear break up time was lesser in students using computers more than 8 hours, normal in students using computers less than 1-2 hours. 


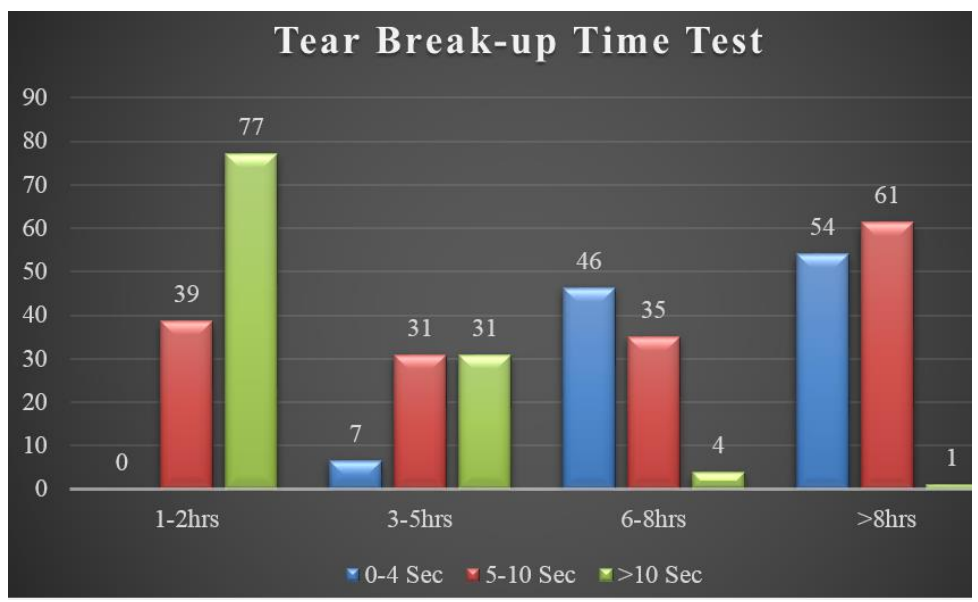

\section{Discussion}

The present study was conducted among the medical students. Total number of students enrolled were 709 the revalence of computer vision syndrome was $54.44 \%$. NIOSH survey (National Institute of Occupational Safety and Health) has reported that visual symptoms occur in 75-90 \% of VDT workers as opposed to $22 \%$ musculoskeletal disorders (carpel tunnel syndrome) in computer users ${ }^{10}$ numerous studies have been done to find out prevalence of computer vision syndrome in university students, but medical students are not always included. Prevalence of $54.44 \%$ indicates the increase in dependency on computers in form of mobile smart phones with their visual display unit by medical college graduate and post graduate students. Lograj et al found prevalence of computer vision syndrome in engineers were $81.9 \%$ and $78.6 \%$ in medical students. ${ }^{11}$ Study conducted by Reddy et al in Malaysia found prevalence of $89.9 \%,{ }^{12}$ but the study does not mention inclusion of medical students. Study conducted by Venkatesh et al found eye strain $(53.9 \%)$ followed by headache $(38.5 \%)$ as disturbing symptoms. ${ }^{13}$ While Bali et al found $81.7 \%$ of the study population had headache. ${ }^{1}$ The difference in the prevalence rate of computer-related problems in various studies depend upon factors like knowledge and awareness levels, workstation set up, degree of immobilization and levels of constrained postures, and practices of workers regarding computer ergonomics ${ }^{15}$. In the present study relation between symptoms of computer vision syndrome and average number of hours spent on computer was studied and it was observed that majority of the symptoms like headache, eyestrain, dry eye, blurred vision, and red eye were having statistically significant association with increasing hours of computer use. It was observed that there was significant association between the duration of computer use and symptoms (Table 6 and Table 8). Prolonged staring at visual display units of computers results in infrequent blinking, thus results on symptoms of dry eye. Resting point of accommodation is the distance at which the eye focuses when there is nothing to look at. It is differs with every individual. JaschinskiKruza (1988) found that uninterrupted viewing of a computer monitor closer than the resting point of accommodation contributed to eye strain. ${ }^{16}$ The ciliary muscle must work two and a half times harder to focus on a monitor 12 inches away than it does to focus at 30 inches (Fischer, 1977). ${ }^{16}$ This results in symtoms like eyestrain, blurred vision for distance after prolonged computer viewing. Study conducted by Lograj et al also found similar results, students who were using computer for 4-6 h were at significantly higher risk of developing redness, burning sensation and dry eyes compared to those who use computer for less than 4 hours. ${ }^{11}$ Shrivastava and Bobhate report found that visual symptoms increased with the increase in working hours on the computer. ${ }^{17}$ It was seen that neck pain and shoulder pain had statistical significant association with the average numbers of hours spent on computer and duration of computer use. (Table 7 and table 9). Lograj et al did not find statistical significance between non ocular symtoms in students using computers more than 6 hours. Neck pain was complained more by students using computers 4 to 6 hours than use more than 6 to 8 hours. ${ }^{11} \mathrm{We}$ found numerous risk factors associated with computer vision syndrome like prolonged glaring at the screen was reported by $68.65 \%$ of students followed by long work duration $(42.78 \%)$ and use of too much mental strength (28.24\%). Too bright screen/light $(23.83 \%)$, external light reflection on the computer screen (11.92\%), poor eyesight (12.44\%), stress $(11.14 \%)$, personal fatigue $(9.07 \%)$ and poor ventilation $(8.03 \%)$. The visual symptoms can largely be resolved with proper management of the environment and by providing proper visual care for the employee using visual display units. ${ }^{18}$ It was observed that $35.23 \%$ students were taking regular breaks to get relief from the computer vision syndrome. Closing eyes $(31.87 \%)$ and using glare screen on the computer $(28.24 \%)$ were the other measures used by the students. $73.1 \%$ of subjects who had CVS symptoms did not use antiglare screen during computer use (P-0.05) in the study conducted by Venkatesh et al. ${ }^{13}$ Our study 
findings similar to Talwar et al who found $85.2 \%$ having symptoms did not use antiglare filters. ${ }^{19}$. According to $\mathrm{Mc}$ Lean et $\mathrm{al}^{20}$ taking regular small breaks may relax accommodation process of the eyes, thereby preventing eyestrain.

Taking regular small breaks may relax accommodation process of the eyes, thereby preventing eyestrain. Taking breaks in between the use of computer was the most common preventive measure taken for relief of symptoms of CVS It was observed that schirmer's test result less than $5 \mathrm{~mm}$ was found in $94(24.35 \%)$ students using computers more than 6 hours. Aurora Gajata et al found among the eyes in the analysis, the Schirmer I test value was less than $5 \mathrm{~mm}$ in $45 \%$ of subjects (dry eye) in the group A which used computers more than 8 hours, less than $10 \mathrm{~mm}$ in $42 \%$ (risk of dry eye), $15 \mathrm{~mm}$ (normal value) in 13\%, compare to group B which ocassionaly used computers, where normal values larger than $15 \mathrm{~mm}$ were found in $73,33 \%$ of the total subjects. ${ }^{21}$ Tear break up time was lesser in students using computers more than 8 hours, normal in students using computers less than 1-2 hours. Bhargava et al in study of oral omega 3 fatty acids in treatment of computer vision syndrome stated that Schirmer's test was abnormal in 33\% symptomatic computer users at baseline. Tear film break up time was abnormal in 55\% symptomatic computer users at baseline before starting the treatment. Report of the Definition and Classification Subcommittee of the International Dry Eye WorkShop (2007) classified low blinking rate resulting in intrinsic cause of evaporative dry eye.

Occupational factors may cause a slow blink rate, representing a risk for dry eye in those working with video display terminals. ${ }^{23}$ The study implies the importance of good working environment and preventive measures to be taken in order to prevent computer vision syndrome. Steps to reduce computer eyestrain have been suggested by the National Institute of Health and Occupational Safety like regular eye examination, frequent conscious blinking, Taking breaks, refocusing on a distant object and minimizing glare.

Limitation of this study was we have taken students for examinations which are symptomatic. considering symptomatic patients would be having positive sign hence they were further evaluated further. Hence there is scope of further comparative study between symptomatic and non-symptomatic students. The backbone of any care program is the capability of the doctors who are providers for that program. ${ }^{5}$ These students are the torch bearers for the future generations. Awareness of visual symptoms is a must amongst these students, incorporation of good visual and postural habits will improve the productivity and prevent visual stress.

\section{Conclusion}

The prevalence of computer vision syndrome amongst medical student was $54.44 \%$. It was observed that there was significant association between the duration of computer use and symptoms. Symptoms increased with longer hours of computer work and other similar devices. This is in line with reports of other studies. $^{23}$

Almost $68.13 \%$ did not use any precautionary measures like consciously closing eye while $71.76 \%$ did not use antiglare screens. Schirmers test result was low as well as tear break up time was reduced in students suffering from computer vision syndrome.

Considering the prevalence of computer vision syndrome in medical students, importance of this topic should be included in curriculum, adequate knowledge and appropriates practices if adopted will surely help the students.

\section{References}

1. Bali J, Neeraj N, Bali RT. Computer vision syndrome: A review. J ClinOphthalmol Res 2014;2:61-8.

2. Rosenfield M. Computer vision syndrome: a review of ocular causes and potential treatments. Ophthalmic Physiol Opt. 2011;1(5):502-515. [PubMed]

3. Blehm C, Vishnu S, Khattak A, Mitra S, Yee RW. Computer vision syndrome: a review. Surv Ophthalmol. 2005;50(3):253-262. [PubMed]

4. Becoming a Squinter Nation, Wall St. Journal, August 17, 2010.

5. Anshel, J 2007, 'Visual ergonomics in the workplace', American Society of Safety Engineers, ASSE professional Development Conference, June 24-27, 2007, Orlando Florida, No: 07-0413.

6. American Optometric Association. Guide to the clinical aspects of computer vision syndrome. St. Louis: American Optometric Association; 1995.

7. Sen A, Richardson S. A study of computer-related upper limb discomfort and computer vision syndrome. J Hum Ergol (Tokyo) 2007;36:45-50.

8. Dogru M, Katakami C, Inoue M. Tear function and ocular surface changes in noninsulin-dependent diabetes mellitus. Ophthalmology. 2001;108:586-92. [PubMed]

9. Jones LT. The lacrimal secretory system and its treatment. Am J Ophthalmol. 1966;62:47-60.

10. Trusiewicz. D; Niesluchowska. M, Makszewska Eyestrain symptoms after work with a computer screen Klin Oczna 1995, 97:343-5.)

11. Logaraj M, Madhupriya V, Hegde SK. Computer vision syndrome and associated factors among medical and engineering students in Chennai. Ann Med Health Sci Res 2014;4:179-85.

12. Reddy SC, Low CK, Lim YP, Low LL, Mardina F, Nursaleha MP. Computer vision syndrome: a study of knowledge and practices in university students. Nepal $J$ Ophthalmol. 2013 Jul-Dec;5(2):161-8. doi:10.3126/nepjoph.v5i2.8707.

13. Soumya Harapanahalli Venkatesh, Anita T Girish, Shashikala, Praveen K, Snigdha M, Rajendra R International Journal of Contemprory Medical Research. A Study of Computer Vision Syndrome at the Workplace Prevalence and Causative Factors. Volume 3 issues august 2016. 
14. Shantakumari N, Eldeeb R, Sreedharan J, Gopal K. Computer Use and Vision. Related Problems Among University Students In Ajman, United Arab Emirate. Annals of medical and health sciences research. 2014;4:258-63.

15. Shrivastava SR, Bobhate PS. Computer related health problems among software professionals in Mumbai: A cross-sectional study. International Journal of Health and Allied Sciences. 2012;1:74.

16. http://www.allscan.ca/ergo/vangle2.htm

17. Shrivastava SR, Bobhate PS. Computer related health problems among software professionals in Mumbai: A cross-sectional study. Int J Health Sci. 2012;1:74-8.

18. Sheedy JE. Vision problems at video display terminals: a survey of optometrists. J Am Optom Assoc 63, 687-692, 1992.

19. Talwar R, Kapoor R, Puri K, Bansal K, Singh S. A study of visual and musculoskeletal health disorders among computer professionals in NCR Delhi. Indian journal of community medicine. 2009;34:326.
20. Mc Lean L, Tingley M, Scott RN, Rickards J. Computer terminal work and the benefits of microbreaks. Applied Ergonomics. 2001;32:225-237.

21. Aurora Gajta), Daniela Turkoanje, Iosif Malaescu, et al. Dry Eye Syndrome Among Computer Users. citation, Physics Conference Physics without frontiers AIP Conf. Proc. doi:10.1063/1.4937263. 2015.

22. bhargava et al. Oral omega-3 fatty acids treatment in computer vision syndrome related dry eye. https://doi.org/10.1016/j.clae.2015.01.007

23. Kowalska M, Zejda JE, Bugajska J, Braczkowska B, Brozek G, Malinska M. Eye symptoms in office employees working at computer stations. Med Pr. 2011;62:1-8. 